\title{
Arquitetura Sensível ao Autista: Quais diretrizes de projeto adotar?
}

\section{Autistic-sensitive architecture: What design guidelines to adopt?}

\author{
Helena Rodi Neumann, Universidade Federal de Mato Grosso do Sul (UFMS) \\ helena.neumann@ufms.br
}

\author{
Larissa Akemi Silva Miyashiro, Universidade Federal de Mato Grosso do Sul \\ (UFMS) \\ larissaakemi0009@gmail.com
}

Larissa Victorino Pereira, Universidade Presbiteriana Mackenzie (UPM)

larissa.vp@ hotmail.com

\begin{abstract}
Resumo
Esta pesquisa tem como objetivo buscar diretrizes projetuais para edifícios distintos voltados ao Transtorno do Espectro Autista (TEA), que possuem transtornos sensoriais, isto é, seus sentidos não compreendem o ambiente de forma típica, gerando disfunções de comportamento e adaptação ao meio. Apresenta-se medidas espaciais para facilitar o dia-a-dia do autista. A fundamentação teórica descreve como é dada a percepção do espaço pelos seres humanos e quais as dificuldades da síndrome. Em seguida, expõe-se uma revisão bibliográfica de autores que já indicaram soluções projetuais benéficas para este público. Dois estudos de caso, então, serão analisados: Centro Integr.Aut, em Campo Grande (MS) e Centro Cultural Sensível, em São Paulo (SP). Após uma discussão sobre as diretrizes presentes nesses, toda informação é sintetizada em uma tabela, a fim de guiar arquitetos que busquem informações sobre como projetar espaços para o público autista.
\end{abstract}

Palavras-chave: Transtorno do Espectro Autista; Transtorno Sensorial; Arquitetura dos Sentidos; Diretrizes para o autismo; Integração Sensorial.

\begin{abstract}
This research aims to seek design guidelines for different buildings for the Autistic Spectrum Disorder (ASD), which have sensory disorders, this means, their senses do not understand the ambience in a typical way, generating dysfunctions to behavioral and adaptation to the environment. Spatial measures are presented to facilitate the daily life of the autistic person. The theoretical basis describes how human beings perceive space and what are the difficulties of the syndrome. Then, a bibliographic review of authors who have already indicated beneficial project solutions for this audience is expound. Besides, two case studies: Centro Integr.Aut, in Campo Grande (MS) and Sensitive Cultural Center, in São Paulo (SP). After a discussion of their present guidelines, all information is summarized in a table, to guide architects seeking information on how to design spaces for the autistic public.
\end{abstract}

Keywords: Autistic Spectrum Disorder; Sensory Disorder; Architecture of the senses; Autism guidelines; Sensory Integration. 


\section{Introdução}

O Transtorno do Espectro Autista, conhecido por sua sigla TEA, é um transtorno neurológico do desenvolvimento. O termo "autismo" vem do grego "autós" ("de si mesmo") e foi utilizado pela primeira vez para definir uma característica da esquizofrenia. Já "espectro" salienta que o comprometimento da síndrome varia de indivíduo para indivíduo, abrangendo dos casos leves aos severos (RAPIN; GOLDMAN, 2008). Impactará, principalmente, na imaginação e na socialização, além de causar uma retração na comunicação e na linguagem.

Não há cura para o autismo, mas diversos tratamentos podem auxiliar o desenvolvimento desses indivíduos e devem ser iniciados o quanto antes. O seu diagnóstico, até o presente momento, é essencialmente clínico, sendo realizado majoritariamente por psiquiatras e psicólogos (SCHWARTZMAN, 2011).

Mundialmente, 70 milhões de pessoas são afetadas pelo transtorno, segundo a Organização Mundial da Saúde (KLIN, 2006). No Brasil, ainda sem um censo preciso, se estima 2 milhões de casos. A cada pesquisa a quantidade de diagnosticados aumenta, tornando imperativo o avanço de estudos na área (SCHWARTZMAN, 2011).

Para a arquitetura, a forma como os autistas captam as informações sensoriais do espaço é o mais relevante, justamente por ser diferente dos neurotípicos (aqueles cujo cérebros funcionam de maneira típica). Devido a um Transtorno no Processamento (GRANDIN, PANEK, 2015), o cérebro assimila a mensagem de maneira diversa, apesar de seus sentidos funcionarem normalmente, impossibilitando, então, uma resposta adaptativa ao meio físico e, consequentemente, acarretando nos sintomas clássicos.

As informações de um ambiente são interpretadas pelos cinco sentidos Aristotélicos: tato, visão, audição, olfato e paladar; além do vestibular (equilíbrio) e proprioceptivo (percepção corporal), incluídos depois dos estudos de Integração Sensorial (AYRES, 1972). O processo de percepção é natural e padrão no comportamento humano, sendo examinado pela Psicologia Ambiental (ORNSTEIN, 2005).

A Arquitetura evidenciará as manifestações do ambiente em cor, textura, temperatura, forma, volume, iluminação, acústica, mobiliário e inúmeros outros fatores. Para o TEA, essas informações devem ser bem evidentes, já que para conseguirem se adaptar a cada espaço, precisam entender facilmente qual é o comportamento esperado.

De forma geral, há duas maneiras com que esses indivíduos reagem ao ambiente: na hipersensibilidade um alto nível de estimulação causará retração, já na hipossensibilidade haverá uma busca pela intensificação desses sentidos. Ressaltando que nem todas as pessoas reagirão da mesma maneira em todas as situações. (NEUMANN, 2017, p.109). 


\subsection{Metodologia}

O artigo iniciará fazendo uma revisão bibliográfica dos principais textos da arquitetura dos sentidos e da integração sensorial. Esta parte será imperativa para enunciar o problema (SERRA, 2006) que a pesquisa visa lançar adiante: quais as diretrizes a se tomar para construir sensivelmente ao TEA. Para isso, se apresentarão dois estudos de caso de projetos na área, método que foi escolhido por ser "um fundamento lógico justificável para se conduzir um estudo [de caso] exploratório, tendo como objetivo o desenvolvimento de hipóteses e proposições pertinentes a inquirições adicionais" (YIN, 2001, p.17), que serão comparados e debatidos no capítulo seguinte. Por fim, a conclusão proporá soluções práticas para o problema discutido.

\section{Fundamentação Teórica}

\subsection{Percepção do Espaço pelo Autista}

Revisitando os ensaios renomados da arquitetura dos sentidos, será explorado as principais diferenças do vivenciamento do espaço pelo autismo. Edward T. Hall é um antropólogo estadunidense que em seu livro "A dimensão oculta" defende que o espaço é um meio de comunicar as pessoas a si mesmas. E é nele que brotará o comportamento, moldado pela cultura (HALL, 1966). No que diz respeito ao TEA, seus sintomas podem se tornar mais ou menos evidentes dependendo do país em que o indivíduo está: "a doença é biológica, mas nunca é somente biológica" (GRINKER, 2010, p.24).

"As pessoas diferem na sua capacidade de visualização - na qualidade e intensidade de seu sistema de imagens visuais" (HALL, 1966, p. XI), sendo os filtros sensoriais pessoais os responsáveis por admitir alguns dados e excluir outros. Para Pallasmaa, arquiteto finlandês, que escreveu "Os olhos da pele" em 1966, o 'campo visual' é a luz em movimento e o 'mundo visual' é a imagem que é obtida da luz no olho humano. Este, seria o responsável por distinguir o relevante do descartável e encontrar sentido a imagem gerada. (PALLASMAA, 1996)

Conforme o arquiteto e escritor dinamarquês Rasmussen afirma, em "Arquitetura vivenciada" de 1986, ao experienciar os sentidos, se acaba assimilando principalmente a parcela mais familiar e se ignorando o restante (RASMUSSEN, 1986). No autismo, como a percepção dos sentidos está intensificada, a tarefa de distinguir os pontos mais relevantes se torna mais exaustiva. Estudos "observaram que pessoas com autismo às vezes prestam mais atenção nos detalhes que as neurotípicas" (GRANDIN, PANEK, 2015, p.132) justamente por esses permitirem um reconhecimento mais fácil.

Zumthor, arquiteto suíço, relata que a 'atmosfera' seria a percepção emocional do espaço e a sensibilidade o modo com que a arquitetura poderia ultrapassar o físico, sendo de fundamental importância a utilização dos sentidos (ZUMTHOR, 2006). Dito isso, “(...) o[s] uso[s] diferentes dos sentidos leva a necessidades muito diversas relativas ao espaço" (HALL, 1966, p. 180), já que "os sentidos não apenas mediam as informações para o intelecto; eles também são um meio de disparar a imaginação e articular o pensamento sensorial." (PALLASMAA, 1996, p.43) 
Os sentidos remotos, aqueles que permitem uma percepção distante, são os olhos, os ouvidos e o nariz. A visão, por exemplo, captará com relativa nitidez informações em até um quilômetro e meio. Enquanto os ouvidos já caem para apenas trinta metros e o olfato necessitará de uma distância ainda mais próxima. (HALL, 1966)

O autista perceberá os sentidos com distância similar, mas com maior intensidade, estando sempre a percepção de tal estímulo em primeiro plano, ao passo que os neurotípicos podem demorar a se aperceber por estarem envolvidos em outra ação.

Os sentidos imediatos são aqueles que dependem do contato da pele, dos músculos e das membranas (HALL, 1966). Pallasmaa (1996) defende que o tato é o modo sensorial que une a experiência de mundo à individualidade. É o sentido mais íntimo e, justamente por este fato, terá uma preeminência de causar ao espectro super-estimulações negativas.

A pele será responsável por captar a textura, o peso, a densidade, a temperatura e a gravidade inerente a qualquer superfície. O paladar, então, seria a origem da experiência sensorial, por ser o tato mais desenvolvido que foi modificado em sabor. (PALLASMAA, 1996)

A visão é o sentido no qual a sociedade como conhecemos hoje mais se apoia para a realização de atividades, mesmo que o 'mundo visual' (PALLASMA, 1996) por vezes transmita informações equivocadas. É importante ter cautela na quantidade de luminosidade para não causar ofuscamento:

Um método eficiente de tortura mental é o uso de um nível de iluminação tão alto e constante que não deixa espaço para o retraimento mental ou para a privacidade, até mesmo a interioridade escura do ego é exposta e violada. (PALLASMAA, 1996, p.43)

O som do espaço é um grande instrumento que coleciona, amplia e transmite (ZUMTHOR, 2006). A audição é interior, incorporadora e onidirecional (PALLASMAA, 1966). E justamente por possuir um impacto tão interno nos indivíduos, é a sensibilidade mais recorrente no TEA.

O olfato é o sentido mais emocional e ligado ao imaginário. Ele se diferencia dos outros pelo potencial de trazer lembranças antigas da memória, muitas vezes relacionadas à infância (PALLASMAA, 1966).

Quanto a percepção da arquitetura por autistas é importante recordar Ayres, terapeuta ocupacional norte-americana, que se dedicou à elaboração da "Teoria de Integração Sensorial", que discorre sobre a habilidade de organizar as informações do ambiente para possibilitar uma resposta adaptativa (AYRES, 1972). Ela observou que indivíduos com disfunções neurológicas, incluindo os autistas, demonstram uma dificuldade em absorver tais informações, não conseguindo se adaptar ao espaço de forma assertiva. Cunhou-se, assim, a Terapia de Integração Sensorial que tem como objetivo desenvolver tais relações sensitivas.

Para o neuropediatra Schwartzman, a Integração Sensorial permite relacionar a percepção, a organização e a interpretação das informações sensoriais (SCHWARTZMAN, 2011, p.297). 
Como os autistas não conseguem assimilar esses itens, para minimizar o problema, se deve gradualmente potencializar o contato deles com cada estímulo. Incluindo, dessa forma, estas características específicas do TEA às estratégias gerais da arquitetura - função, desempenho, conforto e forma (NEUMANN, 2017, p.217).

No livro "O Cérebro Autista", a bióloga e autora Temple Grandin, que está no espectro, traz a sua própria experiência de como percebe os estímulos sensoriais para evidenciar o transtorno do processamento:

Odeio alarmes em geral, de qualquer tipo. Quando eu era criança, o sinal da escola me deixava completamente doida. Era como um obturador de dentista. Sou sensível aos sons. Sons altos. Sons súbitos. Pior, sons altos e súbitos que não estou esperando. Ainda pior, sons altos e súbitos que eu espero, mas não consigo controlar - problema comum em pessoas com autismo. (GRANDIN, PANEK, 2015, p. 77)

A sensibilidade dos autistas impacta em como eles se comportam, se comunicam e interagem com as pessoas e os espaços. No viés arquitetônico, é importante notificá-los quando um estímulo irá impactá-los, os ajudando, assim, a equilibrar o seu físico-emocional. Neste contexto, a arquiteta egípcia Magda Mostafa desenvolveu estudos nas áreas de Arquitetura e Design para auxiliar os autistas. Para ela, o ambiente deve ser controlado sensorialmente, de acordo com as necessidades específicas de cada um deles (MOSTAFA, 2015).

Mostafa elaborou um index que nomeou de "ASPECTSS", cada letra desse termo se refere a uma diretriz projetual. Os termos originais estão na língua inglesa, em tradução livre, seriam: Acústica, Sequenciamento Espacial, Espaço de Fuga, Compartimentalização, Transições, Zoneamento Sensorial e Segurança (MOSTAFA, 2015), como mostra a Tabela 1.

\begin{tabular}{|l|l|}
\hline \multicolumn{1}{|c|}{ DIRETRIZES } & \multicolumn{1}{c|}{ OBJETIVO } \\
\hline 1. Acústica & $\begin{array}{l}\text { Manipulação do ambiente acústico, adequando ruído de fundo, eco e } \\
\text { reverberação. }\end{array}$ \\
\hline 2. Sequenciamento Espacial & Exploração da afinidade dos autistas com a rotina e a previsibilidade. \\
\hline 3. Espaço de Fuga & Promoção de um espaço para uma pausa da estimulação do ambiente. \\
\hline 4. Compartimentação & Determinação e limitação do ambiente sensorial de cada atividade. \\
\hline 5. Transições & Local para recalibração dos sentidos na mudança entre estímulos. \\
\hline 6. Zoneamento Sensorial & Ordenação dos ambientes conforme a sua qualidade sensorial. \\
\hline 7. Segurança & $\begin{array}{l}\text { Promoção de espaços seguros, já que os autistas podem ter a percepção } \\
\text { do ambiente alterada. }\end{array}$ \\
\hline
\end{tabular}

Tabela 1: “ASPECTSS”. Fonte: Adaptada de MOSTAFA, 2015.

Algumas dessas diretrizes merecerão especial destaque. O Zoneamento Sensorial propõe que um projeto deve ser ordenado de acordo com a sua qualidade e quantidade de estimulação (MOSTAFA, 2015). Consoante a esta estratégia, o Sequenciamento Espacial (MOSTAFA, 2015) trata da previsibilidade destes espaços a fim de evitar distrações. Já as Zonas de Transição visam ajudar no retorno do equilíbrio sensorial nas passagens de um espaço de alta estimulação para outro de baixa estimulação e vice-versa (MOSTAFA, 2015). 
Para os autistas, a organização dos espaços conforme os níveis sensoriais facilita o entendimento da funcionalidade, possibilitando o desenvolvimento de vários sentidos. Dessa forma, deve-se promover espaços de baixa, média e alta estimulação, como nos casos a seguir.

\section{Estudos de Caso em Arquitetura Sensível}

Serão apresentados dois estudos de caso que têm como objetivo explicitar a maneira como a arquitetura pode colaborar no desenvolvimento físico e emocional dos autistas, atendendo suas diferenças de processamento sensorial. O primeiro projeto é um centro de apoio que servirá de suporte ao ensino regular, contribuindo com o aprendizado, enquanto o segundo é um centro cultural, que permitirá um contraste de estimulações.

\subsection{Centro INTEGR.AUT}

O Centro Integr.Aut é um espaço de apoio voltado para atender crianças com o Transtorno do Espectro Autista, em Campo Grande - MS (MIYASHIRO, 2021). Situado no bairro São Francisco, o terreno do projeto apresenta uma área de $3.988 \mathrm{~m}^{2}$. O intuito é que apoie o ensino fundamental regular presente na cidade, em seu contraturno. Este projeto foi elaborado consoante as diretrizes gerais da arquitetura e, também, as diretrizes específicas para atender os autistas.

O primeiro contato das crianças com este edifício acontece na Praça Pública, situada no nível intermediário do terreno, funciona como um eixo que define os principais acessos às atividades terapêuticas. Um espaço aconchegante com vegetação, espelho d'água, mobiliários e uma grande cobertura metálica, que permite a incidência de iluminação natural, demonstrada na Figura 1. Tratando-se de um ambiente de transição entre os estímulos urbanos e o centro de apoio.

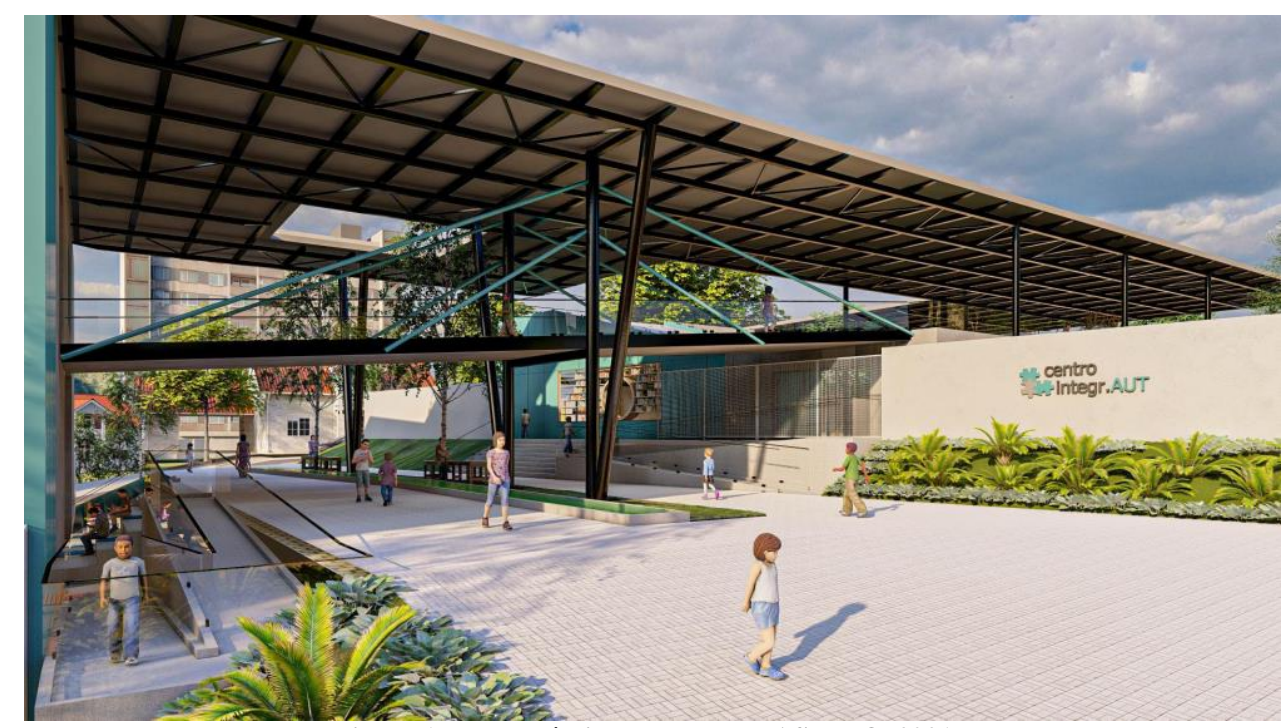

Figura 1: Praça Pública. Fonte: MIYASHIRO, 2021.

Como estratégia de projeto, as ambiências foram organizadas de acordo com a sua qualidade sensorial. O terreno apresenta três zonas visuais importantes: dinâmica, restrita e contemplativa. Com isso, os espaços de média/alta estimulação foram posicionados próximos na dinâmica e, os de média/baixa, na restrita. 
Com relação aos usos externos destacam-se: a Praça de Habilidades, o Jardim Sensorial, o Pomar, o Espaço de Descanso/Contemplação e o Jardim dos Temperos. A Praça de Habilidades tem como objetivo trabalhar com o equilíbrio e a coordenação motora dos autistas. Um espaço de lazer, com equipamentos lúdicos e percursos retilíneos e sinuosos, além de cores estimulantes (como o amarelo).

Em seguida, as atividades internas do Centro Integr.Aut foram organizadas em blocos: Terapêutico Ocupacional, Terapêutico Artístico, Administrativo e Ensino e Convívio Social. Os blocos são conectados por meio de escadas, rampas, passarela e uma grande cobertura metálica independente, em um percurso que integra todos os volumes. Para os autistas, os blocos separados facilitam a compreensão da funcionalidade de cada espaço. Neste trajeto, as crianças vivenciam sensações espaciais diferentes, que vão desde o espaço de fuga até os ambientes de lazer na cobertura.

No bloco Terapêutico Ocupacional encontram-se as salas de psicomotricidade, fisioterapia e terapia ocupacional. A fim de criar uma identidade visual e facilitar a identificação da função, em cada sala há a predominância de uma cor estimulante, a exemplo disso: amarelo, roxo e laranja. Com a intenção de flexibilizar o espaço dessas salas utilizou-se a porta camarão e divisórias móveis para possibilitar grupos menores de trabalho, atendendo casos de extrema dificuldade de contato social.

Já os Espaços de Fuga são caracterizados por apresentarem baixo estímulo sensorial. São ambientes individuais e pequenos, com aproximadamente $6 \mathrm{~m}^{2}$, direcionados para o retorno do equilíbrio físico e emocional dos autistas, como pode ser visto na Figura 2. Um espaço acolhedor, com cores neutras e a esquadria baixa possibilita a entrada de iluminação natural e consolida uma janela-banco. Ademais, a fim de minimizar os ruídos foram utilizados materiais absorvedores: placas de madeira perfuradas, nas paredes, e carpete azul, no piso.

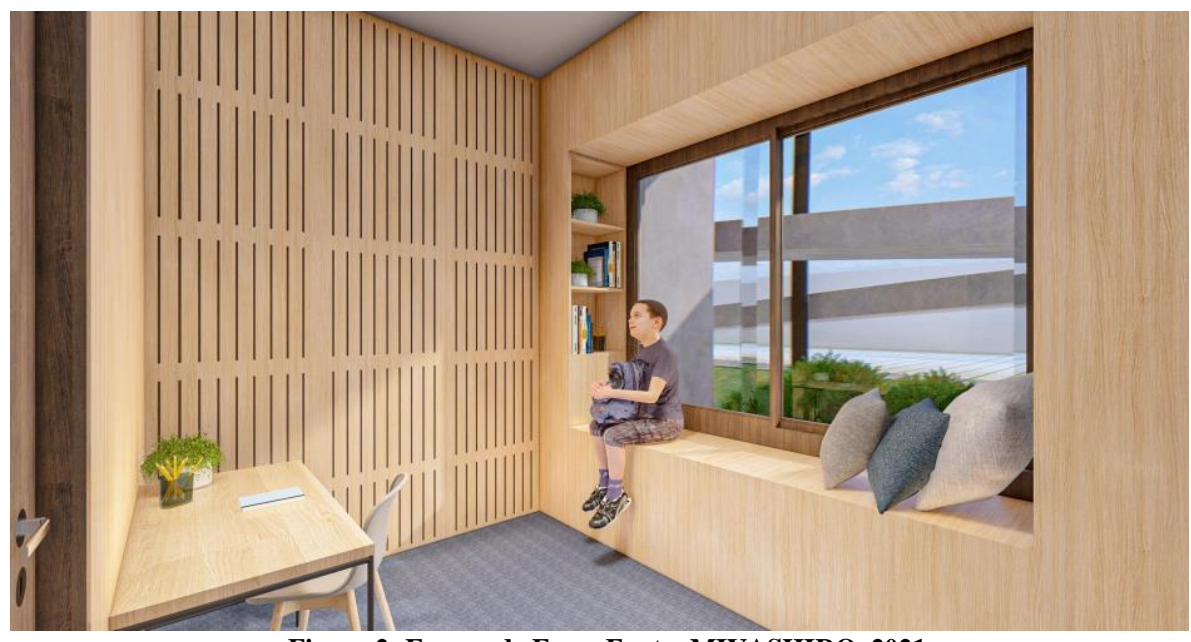

Figura 2: Espaço de Fuga. Fonte: MIYASHIRO, 2021.

A biblioteca deste bloco apresenta uma laje inclinada, caracterizando sua forma e proporcionando um pé-direito alto, com forro de madeira e nuvens acústicas para o controle de ruídos. Um espaço para estudos, com cores neutras e mobiliários dinâmicos. A linearidade da estante dos livros permitiu a criação de bancos com almofadas aconchegantes e nichos circulares 
individuais para as crianças. Sendo o seu mezanino a área de menor estimulação e apresentando grande incidência de iluminação natural devido às largas esquadrias. Este é um espaço de caráter acolhedor, com puffs para as crianças contemplarem a paisagem externa.

Nas salas de psicopedagogia e fonoaudiologia, se necessita de concentração, assim, foram utilizadas esquadrias altas que minimizam as interferências externas. Por fim, ainda no Bloco Terapêutico Ocupacional, foi proposto um pátio central contemplativo que transiciona as atividades de baixa e alta estimulação, como mostra a Figura 3.

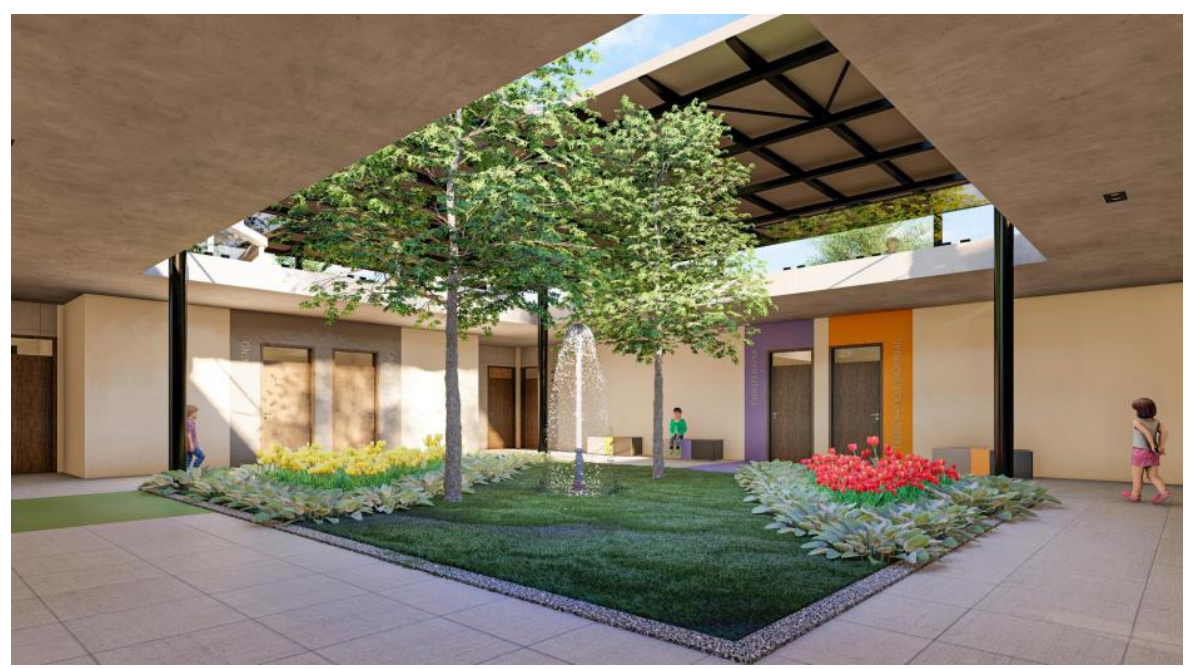

Figura 3: Pátio de Transição Sensorial. Fonte: MIYASHIRO, 2021.

No bloco Terapêutico Artístico situam-se as salas de dança/musicoterapia, arteterapia, multissensorial e refúgio. Na sala de dança/musicoterapia são realizadas atividades de hiperestimulação sensorial, possibilitando o desenvolvimento dos sentidos proprioceptivo e vestibular, por meio do som e da movimentação corporal.

$\mathrm{Na}$ cozinha de ensino, as crianças realizam atividades individuais e em grupo, visando a estimulação e a interação. Um espaço de aprendizado onde a hiper-sensibilidade dos autistas ao tato e ao paladar diminuem por meio da estimulação do contato, manuseio e degustação das hortaliças. Funciona como um laboratório gastronômico que tem como intuito diminuir as restrições alimentares, que são muito comuns em pessoas com transtornos sensoriais.

Em suma, as estratégias adotadas no Centro Integr.Aut tem como viés estimular o autista, de maneira gradual, a desenvolver o processamento dos estímulos sensoriais a partir da realização de atividades as quais envolvem os sentidos. Dessa maneira, as crianças conseguem apresentar uma resposta adaptativa ao ambiente, colaborando nos âmbitos: familiar, educacional e social.

\subsection{Centro Cultural Sensível ao Espectro Autista}

O segundo estudo de caso é o projeto de um Centro Cultural localizado imediatamente à frente da estação de metrô Santana, na capital de São Paulo. Utilizou-se estratégias sensoriais de acolhimento e estimulações de grandezas opostas para atender o autismo (PEREIRA, 2021). 
Uma cobertura estilo muxarabi percorre da calçada até a entrada do edifício, permitindo uma transição gradual que auxiliará o adentramento do usuário autista. Isso se dá pelas aberturas maiores na parte mais externa e, menores, na mais interna, criando uma dica visual e luminosa que será percebida pela sombra no chão e pela temperatura.

O edifício se ergue como um obstáculo entre o eixo de transportes e o jardim central, para permitir um ambiente aberto e público menos estimulante. Como uma barreira, ele protegerá, acústica e oticamente, o jardim central da poluição sonora e visual de Santana. Na conexão entre um espaço e o outro foi implantado um rebaixo rampeado no piso para indicar aos usuários essa diferença de ambiências.

O jardim central propicia um local de convívio público para os indivíduos do espectro treinarem a socialização, já que, comumente, apresentam dificuldade para interagir com desconhecidos e/ou lidar com múltiplas estimulações.

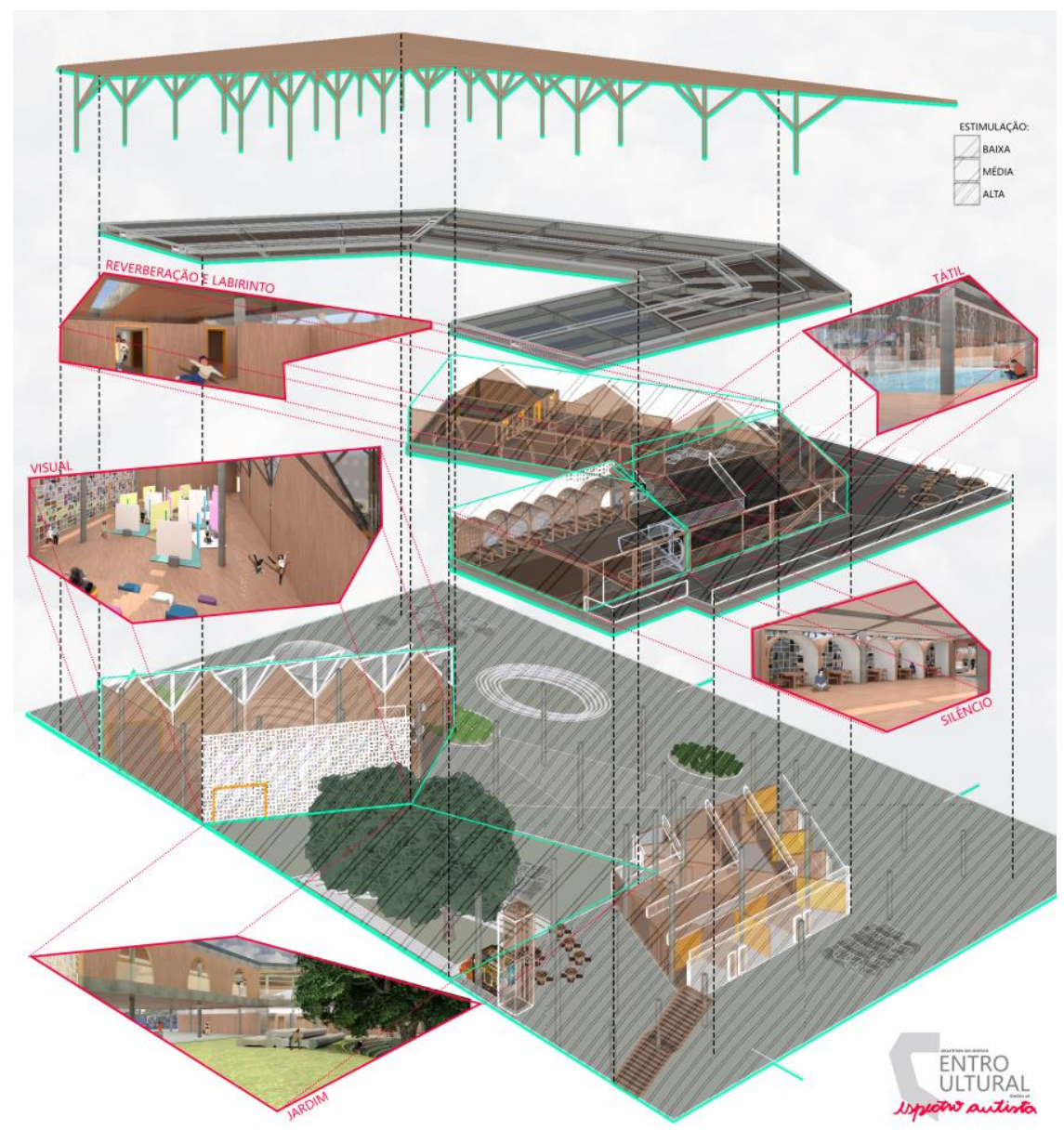

Figura 4: Diagrama de estímulos do Centro Cultural Sensível. Fonte: PEREIRA, 2021.

Internamente, um percurso único em formato de "C" facilita o entendimento proprioceptivo, contendo salas focalizadas em um ou alguns sentidos (Figura 4) que acontecerão de duas formas principais:

I. Criar um espaço que não seja um desafio às pessoas com transtorno sensorial; 
II. Potencializar a busca pela estimulação dos sentidos, auxiliando a criação de um repertório de sensações familiares.

Na categoria I, a sala do Silêncio promove a minimização de ruídos através de espuma absorvedora, instalada no forro e na parte superior do mobiliário. Somado a isso, as paredes voltadas ao terminal são duplas de madeira e preenchidas com lã mineral, para isolamento acústico.

Os outros sentidos também foram minimizados. As cores são neutras e claras (madeira, cinza, branco e azul-claro) para potencializar a tranquilidade do ambiente. Também se evitou materiais que exalem aromas fortes. As superfícies próximas ao toque são suaves, ou seja, o mais lisas possíveis, para diminuição da estimulação tátil.

A categoria II possui múltiplos ambientes. A sala Tátil (Figura 5) é de estimulação sensorial. Seu piso é de seixos (pedras pequenas e lisas) e a parede dupla é revestida de granito rústico (pedras grandes e ásperas), para propiciar texturas diferentes para a exploração tátil e visual do usuário. Ademais, ela refletirá o ruído de água criado no ambiente, extremamente positivo.

Em sua cobertura há uma laje alagada que, por meio de chuveiros lineares, descerá em um espelho d'água. A água que cai foi aquecida pelo sol contrastará com a do espelho d'água, que está fria. $\mathrm{O}$ cair e o correr da água serão, além de estimulantes táteis, a fonte do ruído buscado.

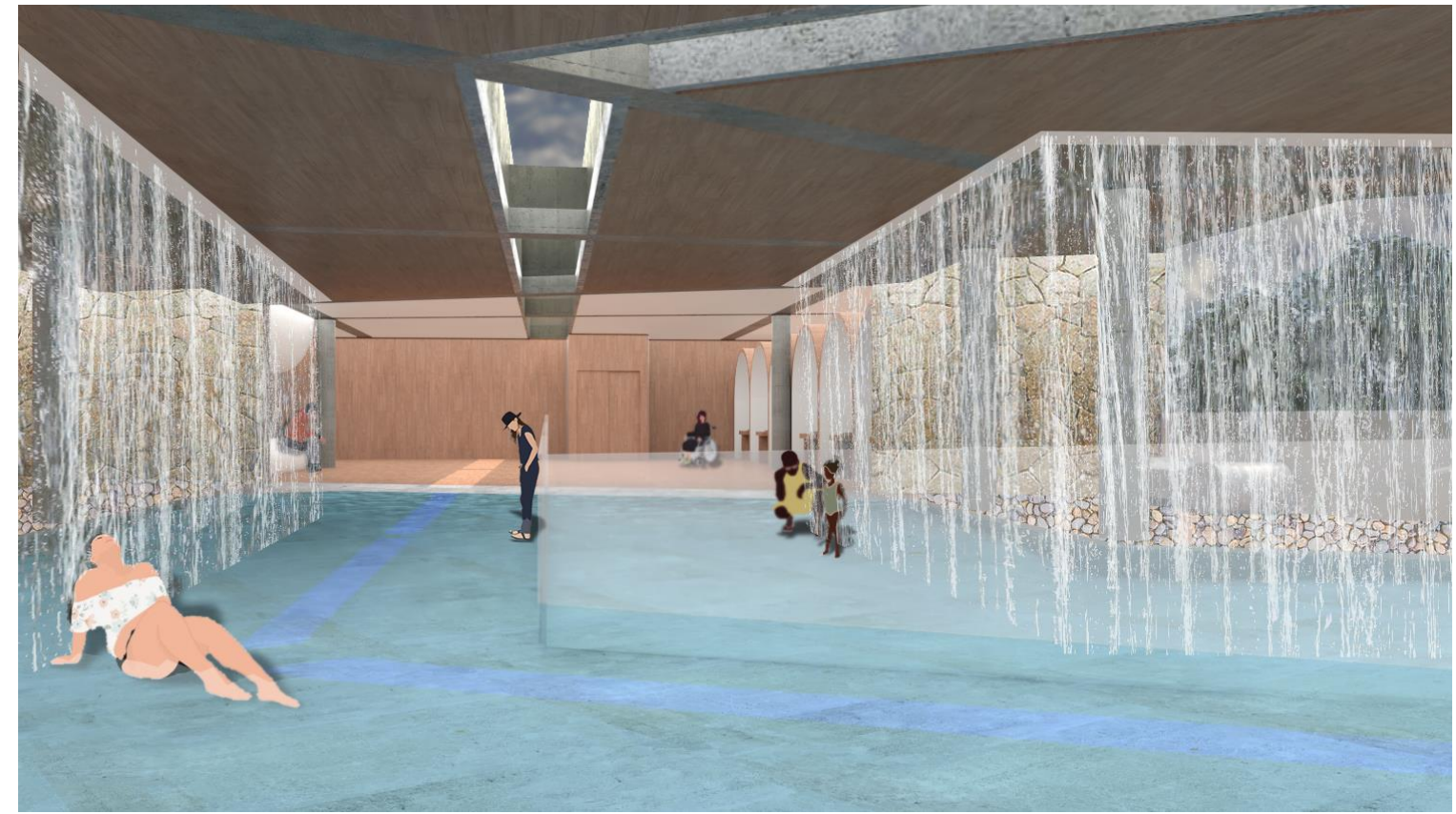

Figura 5: Sala Tátil do Centro Cultural Sensível. Fonte: PEREIRA, 2021.

No Labirinto trabalhou-se a dificuldade de localização espacial (sentidos proprioceptivo e vestibular). Placas de madeira foram pintadas com tinta epóxi para guiar o usuário pelas cores: as paredes voltadas para a frente estão pintadas de azul; as voltadas à esquerda, de laranja; à direita, de roxo e; à trás, de cinza. 
$\mathrm{Na}$ sala de Reverberação criou-se dois pequenos ambientes com contraste sensorial. $\mathrm{Na}$ primeira, revestiu-se forro e paredes com cerâmica (alta reverberação de ruídos) e, na segunda, com espuma absorvedora (alta absorção de ruídos). Uma fonte sonora produz o mesmo som para os dois ambientes. Tornando possível a percepção de como o espaço e os materiais influenciam no comportamento do som, além de permitir que os autistas ampliem seu repertório de sensações.

A sala Visual possui um grande vitral colorido (roxo, laranja e azul) que permite a entrada de luz natural. De manhã e à tarde o sol irá incidir diretamente e poderá causar ofuscamento, criando uma estimulação visual proposital. Ao passo que a noite, a quantidade de luz não será tão agressiva.

Esse espaço tem como função a exibição de arte. Os cavaletes são de fundo branco e, a cada trecho, três cilindros iluminados emitem as cores primárias da luz (azul, verde e vermelho). Cabe aos usuários os ligarem ou desligarem (coordenação motora fina), possibilitando, dessa forma, a exploração do ciclo cromático que alterará a obra temporariamente. A dinamicidade também permite a busca ou o bloqueio da estimulação.

Ainda, há uma arquibancada de contemplação de compensado de madeira que possui assentos estofados de diferentes materiais (como seda, malha, percal, lona) para adaptação tátil. Na frente do terminal e no jardim central, adotou-se vegetações com espécimes de cheiros e gostos díspares para exploração sensorial, como uma amoreira e uma pitangueira e canteiros de hortelã, manjericão e alecrim. Desse modo, ao oferecer múltiplas situações sensoriais, se espera permitir ao espectro autista um maior repertório que facilite sua assimilação do dia-a-dia.

\section{Resultados e Discussão}

\subsection{Novos ambientes voltados ao autista}

Nos dois estudos de caso que foram demonstrados, fica evidente a criação de espaços diferenciados, que não são usuais em projetos arquitetônicos tradicionais, mas voltados às necessidades específicas dos usuários autistas.

No Centro Integr.Aut foi descrito o Espaço de Fuga, uma pequena sala de caráter individual, para reestabelecimento do equilíbrio emocional. Da mesma forma, o Centro Cultural Sensível apresenta a Sala do Silêncio que, apesar de não ser totalmente fechada e individual, devido ao caráter público do programa, também é um local de hipossensibilização. Em meio a um espaço urbano agitado, o autista encontraria ali um refúgio à poluição sensorial, proporcionada pelo isolamento acústico, as cores e texturas suaves.

Toda forma de estimulação sensorial ao autista pode ser bem-vinda, mas se feita de maneira gradual, porque se muito intensa ou repentina, pode causar forte desequilíbrio emocional ao indivíduo. Portanto, espaços "neutros", para resgate de equilíbrio e tranquilidade, são fundamentais para possibilitar refúgios aos usuários autistas, não só nos projetos citados neste artigo, mas em diversos locais da cidade. 


\subsection{Arquitetura dos sentidos para autistas}

Discute-se, então, as diretrizes projetuais aos autistas a partir de cada sentido humano. Do ponto de vista do paladar, o Centro Integr.Aut apresenta na área externa um Jardim de Temperos e um Pomar de fácil acesso aos usuários. A proposta é a experimentação de diferentes sabores e texturas de alimentos, a estimulação olfativa, pelos cheiros distintos e estimulantes, e o desenvolvimento do tato e da coordenação motora ampla, ao trabalhar com a terra.

A escolha dos revestimentos internos é fundamental para a percepção tátil do espaço. Um piso frio, como o cerâmico, pode ser bem impactante aos pés descalços, devido à baixa temperatura e deve ser evitado em espaços para tranquilidade. Já, por exemplo, o piso vinílico ou de madeira é atérmico, e por isso não fica tão frio, sendo ideal para tais espaços.

$\mathrm{Na}$ parede, revestimentos mais rústicos passam indiretamente uma intenção descontraída, enquanto superfícies lisas e brilhantes tornam o ambiente mais formal. Dessa maneira, o uso do local deve ser levado em conta para a escolha do material. O Centro Cultural propôs diferentes texturas de revestimentos em um mesmo ambiente para exploração tátil e visual.

O olfato é o sentido mais primordial. Memórias antigas, já parte do inconsciente, podem ser relembradas a partir de aromas do ambiente. Os cheiros familiares são os mais tranquilizadores, como de terra molhada. Já os novos podem causar estranheza, tornando-se importantes para estimulação sensorial. Por esse motivo, nos dois projetos analisados foram adotados aromas de temperos e frutos nos jardins, além da água corrente.

Os projetos poderiam utilizar aromas artificiais para ambientes em busca da criação de uma identidade própria, que seria reconhecida sempre que se retornasse ao local, solução comumente adotada por hotéis, visando com que o hóspede se sinta em casa.

A visão é considerada o sentido mais importante do Homem no processo de percepção do espaço. Identifica-se as dimensões do ambiente, os materiais de revestimento, as cores, os mobiliários internos e a sua disposição. Em relação as dimensões, os espaços com pé-direito baixo são mais confortáveis, tranquilizadores; enquanto os com o pé-direito alto são imponentes, concedendo importância ao espaço. De forma similar, salas muito grandes são menos confortáveis que as pequenas. As minissalas (NEUMANN, 2017, p.330) oferecem bem menos informações ao usuário, o tranquilizando.

Sobre a audição, é fundamental garantir um ótimo isolamento dos ruídos externos. Para que, como no Centro Cultural, o edifício funcione como uma barreira, isolando a poluição sonora urbana. A este fim, as paredes devem ser de material isolante e, se vazadas, devem apresentar um preenchimento de lã mineral ou rocha.

Depois, se deve separar os espaços para música dos demais, cujo principal desafio é o controle de ruídos. No projeto Integr.Aut, nas salas para aulas de música e dança, torna-se fundamental o equilíbrio sonoro por meio da utilização de materiais de revestimento rígidos e, outros, macios. 
Não sendo possível adotar apenas um material para seu interno, principalmente apenas rígidos que tornariam a sala muito reverberante e incomodativa aos autistas.

O som deve ser distribuído de forma homogênea no espaço, através de caixas de som embutidas no forro. Estas não devem ser posicionadas nos cantos, que sofrem muitas distorções sonoras devido à proximidade entre as paredes, local que pelo mesmo motivo não será adequado a alunos com hiper-sensibilidade ao som. Uma solução é "quebrar" o ângulo reto do canto com um chanfro ou acrescentar um material absorvedor neste ponto.

Nas salas tradicionais é necessário controlar os ruídos, principalmente porque muitos autistas são fontes sonoras em si, já que falam alto e/ou gritam de forma involuntária. Materiais absorvedores nos forros ou nas partes superiores das paredes podem ajudar muito neste controle.

Além disso, deve-se controlar vibrações, que são ondas sonoras não audíveis, mas muito importunas a este público. Elas passam pela estrutura até os pisos e as paredes, sendo necessário a aplicação de manta resiliente (ou acabamento vinílico) fazendo a curva no rodapé até a altura dos ombros (1,10 metros), evitando que o apoiar nas paredes seja perturbador.

O sentido proprioceptivo se revela nos autistas em atrasos no desenvolvimento motor, como, por exemplo, dificuldades em subir degraus de escadas. Dessa forma, é necessário oferecer no espaço arquitetônico desafios ao deslocamento corporal adequado, para que treinem essas habilidades. O centro Integr.Aut apresenta diversos caminhos pelo edifício, através de rampas, pontes, passarela, como um estímulo a percorrer. É possível tirar partido da topografia, a fim de criar espaços desafiadores e estimulantes ao corpo.

Já a tranquilidade é estar em um ambiente conhecido e sem desafios ao corpo humano. Sem dificuldades de movimento nem desconfortos térmicos. Uma diretriz fundamental trabalhada em ambos os estudos de caso foi a entrada gradual ao edifício, que torna menos agressiva a mudança de local e estímulos.

Por fim, o sentido vestibular se relaciona com o equilíbrio físico do corpo. Muitos autistas têm medo de altura, logo, edifícios que oferecem diferentes pontos de vista, em diversos níveis do solo, como o Centro Integr.Aut, realizam uma estimulação gradual benéfica. Rampas leves, como a proposta na entrada do Centro Cultural, demarcam a entrada e oferecem uma pequena quebra de equilíbrio intencional.

\section{Conclusões Finais}

Como conclusão final desta pesquisa, apresenta-se uma tabela síntese com diretrizes projetuais para uma arquitetura sensível, voltada ao usuário com TEA. Esta tabela foi organizada a partir de cada sentido e considerando a sensação desejada no espaço: estimulação ou tranquilidade. As propostas se referem diretamente às identificadas nos projetos analisados anteriormente, porém, as diretrizes são postas de forma mais genérica para serem replicáveis a projetos futuros voltados a este público. 


\begin{tabular}{|c|c|c|c|}
\hline SENTIDO & SENSAÇÃO & PROPOSTAS & DIRETRIZES PROJETUAIS \\
\hline \multirow[t]{2}{*}{$\begin{array}{c}1 . \\
\text { Paladar }\end{array}$} & Estimulação & $\begin{array}{l}\text { - Jardim de Temperos; } \\
\text { - Pomar; } \\
\text { - Canteiros com } \\
\text { Especiarias; } \\
\text { - Cozinha de Ensino. }\end{array}$ & $\begin{array}{l}\text { - Plantas comestíveis ou árvores } \\
\text { frutíferas de fácil acesso, para } \\
\text { estimular a experimentação de novos } \\
\text { sabores; } \\
\text { - Ao ver a fruta ou o vegetal na } \\
\text { natureza, torna-se um maior convite a } \\
\text { comer; } \\
\text { - Fazer a própria comida, ou "brincar" } \\
\text { com esta pode facilitar a aceitação de } \\
\text { alimentos. }\end{array}$ \\
\hline & Tranquilidade & $\begin{array}{l}\text { - Pomar; } \\
\text { - Cozinha de Ensino. }\end{array}$ & $\begin{array}{l}\text { - Ter a disposição e a vista alimentos já } \\
\text { conhecidos e frescos. } \\
\text { - Ao fazer a própria comida, é possível } \\
\text { selecionar o que se gosta e tem } \\
\text { costume de comer. }\end{array}$ \\
\hline \multirow[b]{2}{*}{$\begin{array}{c}2 . \\
\text { Tato }\end{array}$} & Estimulação & $\begin{array}{l}\text { - Salas do Bloco } \\
\text { Terapêutico; } \\
\text { - Jardim Sensorial. }\end{array}$ & $\begin{array}{l}\text { - Materiais com texturas mais rústicas } \\
\text { para mostrar descontração do espaço; } \\
\text { - Salas com temperatura mais quente } \\
\text { para estimulação; } \\
\text { - Pisos frios para serem sentidos com } \\
\text { pés descalços; } \\
\text { - Jardins sensoriais, onde se pisa em } \\
\text { diferentes materiais para estimulação. } \\
\text { - Espaços com diferentes texturas para } \\
\text { percepção dos contrastes. }\end{array}$ \\
\hline & Tranquilidade & $\begin{array}{l}\text { - Sala do Silêncio; } \\
\text { - Espaço de Fuga; } \\
\text { - Áreas de Descanso } \\
\text { e Contemplação. }\end{array}$ & $\begin{array}{l}\text { - Materiais com texturas lisas e polidas } \\
\text { para indicar um espaço formal; } \\
\text { - Pisos atérmicos (madeiras, vinílico) } \\
\text { para pouco contraste de temperatura; } \\
\text { - Salas com temperatura mais baixa } \\
\text { para relaxamento. }\end{array}$ \\
\hline \multirow[b]{2}{*}{$\begin{array}{l}3 . \\
\text { Olfato }\end{array}$} & Estimulação & $\begin{array}{l}\text { - Pátio Interno; } \\
\text { - Jardim de Temperos; } \\
\text { - Pomar; } \\
\text { - Canteiros com } \\
\text { Especiarias; } \\
\text { - Cozinha de Ensino. }\end{array}$ & $\begin{array}{l}\text { - Novos cheiros são estimulantes, como } \\
\text { de frutas, temperos e comida; } \\
\text { - Vegetações com novos cheiros. }\end{array}$ \\
\hline & Tranquilidade & - Idem. & $\begin{array}{l}\text { - Aroma artificial ambiente para criar } \\
\text { uma identidade do local, que passa a } \\
\text { ser reconhecido pelo cheiro; } \\
\text { - Cheiros conhecidos de frutas, } \\
\text { temperos e comida, que são calmantes. }\end{array}$ \\
\hline
\end{tabular}




\begin{tabular}{|c|c|c|c|}
\hline SENTIDO & SENSAÇÃO & PROPOSTAS & DIRETRIZES PROJETUAIS \\
\hline & Estimulação & $\begin{array}{l}\text { - Biblioteca; } \\
\text { - Salas de Música; } \\
\text { - Sala Visual; } \\
\text { - Exposição de Obras } \\
\text { de Arte. }\end{array}$ & $\begin{array}{l}\text { - Espaços com pé-direito alto e grande } \\
\text { volume são estimulantes; } \\
\text { - Uso de cores vivas, como vermelho, } \\
\text { laranja e amarelo; } \\
\text { - Revestimentos e vitrais coloridos para } \\
\text { grande estimulação; } \\
\text { - Mobiliário rígido em material frio } \\
\text { (concreto) com poucas superfícies de } \\
\text { apoio; } \\
\text { - Espaços menores com muitas } \\
\text { informações visuais, por exemplo: } \\
\text { diversos quadros nas paredes. }\end{array}$ \\
\hline $\begin{array}{c}4 . \\
\text { Visão }\end{array}$ & Tranquilidade & $\begin{array}{l}\text { - Mezanino da } \\
\text { Biblioteca; } \\
\text { - Espaço de Fuga; } \\
\text { - Sala do Silêncio; } \\
\text { - Belas paisagens. }\end{array}$ & $\begin{array}{l}\text { - Espaços com pé-direito baixo e } \\
\text { minissalas, com poucas informações, } \\
\text { são tranquilizantes; } \\
\text { - Uso de cores neutras e claras, como } \\
\text { azul e verde; } \\
\text { - Oferecer possibilidade de controle } \\
\text { sobre a iluminação; } \\
\text { - Mobiliário almofadado, em material } \\
\text { macio com diversas superfícies de } \\
\text { apoio, como um "abraço"; } \\
\text { - Espaços mais amplos com poucas } \\
\text { informações visuais; } \\
\text { - Belas paisagens para tranquilidade. }\end{array}$ \\
\hline & Estimulação & $\begin{array}{l}\text { - Salas para Música e } \\
\text { Dança; } \\
\text { - Salas para } \\
\text { Experimentação } \\
\text { Sonora (Reverberante } \\
\text { e Anecóica); } \\
\text { - Chuveiros Lineares. }\end{array}$ & $\begin{array}{l}\text { - Garantir bom isolamento das fachadas } \\
\text { para evitar poluição sonora; } \\
\text { - Em salas para músicas, usar ambos } \\
\text { revestimentos absorvedores e isolantes } \\
\text { para equilíbrio sonoro; } \\
\text { - Salas de Experimentação das } \\
\text { sensações sonoras (espaço reverberante } \\
\text { contínuo a um absorvedor). }\end{array}$ \\
\hline $\begin{array}{c}5 . \\
\text { Audição }\end{array}$ & Tranquilidade & $\begin{array}{l}\text { - Salas tradicionais, } \\
\text { considerando controle } \\
\text { de ruídos e vibrações; } \\
\text { - Sala do Silêncio; } \\
\text { - Espaços de Fuga. }\end{array}$ & $\begin{array}{l}\text { - Garantir bom isolamento das fachadas } \\
\text { para evitar poluição sonora; } \\
\text { - Nas salas de música, fazer a } \\
\text { distribuição das caixas de som de } \\
\text { forma a obter som homogêneo, } \\
\text { evitando os cantos; } \\
\text { - Fazer chanfros nos cantos das salas } \\
\text { ou usar material absorvedor nestes } \\
\text { pontos; } \\
\text { - Controle de ruídos em demais } \\
\text { ambientes, com uso de materiais } \\
\text { absorvedores (fofos ou fibrosos) no } \\
\text { forro e na parte superior das paredes; } \\
\text { - Controle de vibrações com } \\
\text { revestimentos resilientes em paredes. }\end{array}$ \\
\hline
\end{tabular}




\begin{tabular}{|c|c|c|c|}
\hline SENTIDO & SENSAÇÃO & PROPOSTAS & DIRETRIZES PROJETUAIS \\
\hline & Estimulação & $\begin{array}{l}\text { - Edifício como } \\
\text { Percurso; } \\
\text { - Praça de Habilidades; } \\
\text { - Labirinto. }\end{array}$ & $\begin{array}{l}\text { - Estimulação corporal através de } \\
\text { percursos no edifício, como rampas, } \\
\text { passarelas e escadas; } \\
\text { - Ambientes externos para estímulo } \\
\text { físico e motor; } \\
\text { - Labirinto como desafio sensorial. }\end{array}$ \\
\hline $\begin{array}{c}6 . \\
\text { Propriocepção }\end{array}$ & Tranquilidade & $\begin{array}{l}\text { - Entrada gradual e } \\
\text { coberta; } \\
\text { - Zonas de transição } \\
\text { com pátios internos; } \\
\text { - Zoneamento } \\
\text { funcional dos blocos. }\end{array}$ & $\begin{array}{l}\text { - Entrada no edifício de forma gradual } \\
\text { e coberta; } \\
\text { - Zonas de transição para neutralizar } \\
\text { diversos estímulos, com espaços sem } \\
\text { desafios fisiológicos ao corpo. }\end{array}$ \\
\hline & Estimulação & $\begin{array}{l}\text { - Rampa leve de } \\
\text { acesso; } \\
\text { - Cobertura acessível. }\end{array}$ & $\begin{array}{l}\text { - Rampa leve de acesso para quebra do } \\
\text { equilíbrio. } \\
\text { - Visuais em diferentes alturas em } \\
\text { edifícios com mais de um pavimento; } \\
\text { - Possibilitar acesso a cobertura. }\end{array}$ \\
\hline $\begin{array}{c}7 . \\
\text { Vestibular }\end{array}$ & Tranquilidade & $\begin{array}{l}\text { - Espaços com pisos } \\
\text { planos; } \\
\text { - Itens de segurança } \\
\text { para piso. }\end{array}$ & $\begin{array}{l}\text { - Espaços com pisos planos, para } \\
\text { tranquilidade com o conhecido, sem } \\
\text { desafios; } \\
\text { - Itens de segurança para piso, para } \\
\text { evitar escorregar. }\end{array}$ \\
\hline
\end{tabular}

Tabela 2: Diretrizes projetuais para Arquitetura Sensível ao Autista. Fonte: Autoras, 2021.

É necessário se estabelecer diretrizes projetuais para os indivíduos do Espectro Autista. Para uma boa arquitetura diversos condicionantes devem ser levados em consideração, entre estes, as necessidades particulares de seus futuros usuários. Portanto, as diretrizes projetuais descritas nesta pesquisa podem beneficiar diversos projetos para este público. É fundamental considerar a inserção destas pessoas em locais que os acolham para que se sintam cada vez mais seguros a frequentar os espaços públicos e diferenciados da cidade. Permitindo, assim, que a arquitetura colabore com a vida normal dos indivíduos autistas, cumprindo mais um viés de seu potencial de transformação social. 


\section{Referências}

AYRES, Anna Jean. Sensory Integration and Learning Disorders. 1. ed. Western Psychological Services, 1972. p. 1-181.

GRANDIN, Temple; PANEK, Richard. O cérebro autista: Pensando através do espectro. 1. ed. Rio de Janeiro: Editora Record, 2015.

GRINKER, Roy Richard. Autismo: um mundo obscuro e conturbado. Tradução de Catharina Pinheiro. São Paulo: Larrousse do Brasil, 2010.

HALL, Edward. A dimensão oculta. Coleção A, São Paulo: Martins Fontes, 1966.

KLIN, Ami. Autismo e síndrome de Asperger: uma visão geral. Rev. Bras. Psiquiatr., São Paulo, v.28, supl.1, p.s3-s11, May 2006. Available $\quad$ from $<$ http://www.scielo.br/scielo.php?script=sci_arttext\&pid=S1516-

$44462006000500002 \& \operatorname{lng}=$ en\&nrm=iso $>$ Acesso

17 Jan. 2021. http://dx.doi.org/10.1590/S1516-44462006000500002.

MIYASHIRO, Larissa Akemi Silva. Centro Integr.Aut: Centro de apoio para crianças com Transtorno do Espectro Autista em Campo Grande - MS. Trabalho final de conclusão de curso. Graduação em Arquitetura e Urbanismo, Universidade Federal de Mato Grosso do Sul, Campo Grande, 2021.

MOSTAFA, Magda. The Autism ASPECTSS Design Index. 2015. Disponível em: <https://www. autism.archi/aspectss>. Acesso em: 27 mar. 2021.

NEUMANN, Helena Rodi. Projeto acústico para transtornos sensoriais. Tese (Doutorado em Arquitetura e Urbanismo). Universidade Presbiteriana Mackenzie, São Paulo, 2017.

ORNSTEIN, Sheila Walbe. Arquitetura, urbanismo e Psicologia Ambiental: uma reflexão sobre dilemas e possibilidades da atuação integrada. Psicol. USP, São Paulo, v. 16, n. 12, p. 155-165, $2005 . \quad$ Available from $<$ http://www.scielo.br/scielo.php?script=sci_arttext\&pid=S0103-

$65642005000100017 \& \operatorname{lng}=$ en\&nrm=iso $>$.

Acesso em 15 Jan. 2021. http://dx.doi.org/10.1590/S0103-65642005000100017.

PALLASMAA, Juhani. Os olhos da pele: A arquitetura e os sentidos. 1a edição, Porto Alegre: Bookman, 2011.

PEREIRA, Larissa Victorino. Arquitetura dos sentidos: Centro cultural sensível ao espectro autista. Trabalho final de conclusão de curso. Graduação em Arquitetura e Urbanismo, Universidade Presbiteriana Mackenzie, São Paulo, 2021.

RASMUSSEN, Steen Eiler. Arquitetura vivenciada. São Paulo: Martins Fontes, 1986.

RAPIN, Isabelle; GOLDMAN, Sylvie. A escala CARS brasileira: uma ferramenta de triagem padronizada para o autismo. J. Pediatr. (Rio J.), Porto Alegre, v. 84, n. 6, p. 473475, Dec. 2008. Available from $<$ http://www.scielo.br/scielo.php?script=sci_arttext\&pid=S0021-

$75572008000700001 \& \operatorname{lng}=$ en $\&$ nrm $=$ iso $>$. access on 10 Jan. 2021. https://doi.org/10.1590/S0021-75572008000700001. 
SCHWARTZMAN, José Salomão; ARAÚJO, Ceres Alves de. Transtornos do Espectro do Autismo. 1. ed. São Paulo: MEMNON, 2011.

SERRA, Geraldo. Pesquisa em Arquitetura e Urbanismo. Edusp e Mandarim, 2006.

YIN, Robert. Estudo de caso: planejamento e métodos. 2 ed. Porto Alegre: Bookman, 2001.

ZUMTHOR, Peter. Atmosferas. Entornos arquitetônicos - as coisas que me rodeiam. Barcelona: Gustavo Gili, 2006.

\section{Sobre as autoras}

\section{Helena Rodi Neumann}

Doutora em Arquitetura e Urbanismo pela Universidade Presbiteriana Mackenzie (2017). Possui graduação em Arquitetura e Urbanismo pela Escola da Cidade (2010). Atualmente é professora Adjunta do curso de Arquitetura e Urbanismo da Universidade Federal de Mato Grosso do Sul UFMS. É pesquisadora na área de Projeto Arquitetônico e Conforto Ambiental. Coordenadora do grupo de Pesquisa em Avaliação Pós-Ocupação - P.APO.

ORCID: 0000-0001-6038-7786

\section{Larissa Akemi Silva Miyashiro}

Bacharel em Arquitetura e Urbanismo pela Universidade Federal de Mato Grosso do Sul UFMS. É pesquisadora na área de Projeto Arquitetônico e Conforto Ambiental. Membro do Grupo de Pesquisa em Avaliação Pós-Ocupação - P.APO.

ORCID: 0000-0003-3679-9021

\section{Larissa Victorino Pereira}

Bacharel em Arquitetura e Urbanismo pela Universidade Presbiteriana Mackenzie - UPM. É pesquisadora na área de Projeto Arquitetônico e Conforto Ambiental. Membro do Grupo de Pesquisa em Avaliação Pós-Ocupação - P.APO.

ORCID: 0000-0002-3809-815X 